\title{
Understanding the burden in communication through a short-term education program with practical experiences
}

- Focus on VAS differences among method and transition through experience -

\author{
Tamotsu Imura *, Yugo Narita**, Michiko Nakai ***Yuji Tanaka **** \\ and Takemasa Ishikawa $* * * * *$ \\ * Faculty of Nursing and Rehabilitation, Chubu Gakuin University, 2-1, Kirigaoka, Seki-shi, Gifu 501-3993, Japan \\ t-imura@umin.ac.jp \\ ** Course of Nursing Science, Graduate School of Medicine, Mie University, 2-174 Edobashi, Tsu-shi, Mie 514-8507, Japan \\ *** Faculty of Nursing, Suzuka University of Medical Science, 3500-3 Minamitamagaki-cho, Suzuka, Mie 513-8670, Japan \\ **** Health Supporting Center, Aichi University of Education, 1, Hirosawa, Igaya-cho, Kariya-shi, Aichi 448-8542, Japan \\ *****Department of Nursing, Mie University Hospital, Mie University, 2-174 Edobashi, Tsu-shi, Mie 514-8507, Japan
}

\begin{abstract}
We designed and implemented a short-term educational program with practical experiences for students on communication support for patients with neurodegenerative disorders. We aimed to (1) clear and dissolve the factor of burden in communication through students' understanding, (2) evaluate and maintain the effects of understanding this burden through practical experiences. Two lectures and one experience session that included a three method communication trial was conducted four times every 6 months. The students learned this program two consecutive times. The burden was recorded and evaluated by a visual analog scale (VAS) before/after using the three methods. A difference in the trend between the beginners' and experienced group was found - the former felt that communication would be possible by using some tools before the experience. While comparing the before/after experience, the significant differences found in the beginners' group was higher as compared to the experienced group. Almost no significant difference was found between (a) the same 1st and 2nd item and (b) the after 1st and before 2nd experience. The VAS of the before experience had high significant difference before it eventually transitioned to low. The burden was low while using any tool with a good timing or signal to the device or partner. We presume that participants understood the factor of burden and found a solution during the 1st experience to realize it at re-learning. Therefore, maintaining experiences 6 months apart, suggested the effect of repeated learning. Keywords: Amyotrophic Lateral Sclerosis (ALS), Augmentative and Alternative Communication (AAC), Burden, Experience, VAS
\end{abstract}

\section{INTRODUCTION}

Patients with neurological diseases such as advanced amyotrophic lateral sclerosis (ALS) have difficulty in communication. They need Augmentative and Alternative Communication (AAC). There is a conceptual scheme of AAC in Japan, as shown in Figure 1.[1] AAC is a general inclusive concept, covering non-information technology (IT) methods and IT products; and includes personal computers, portable voice output communication aids, and Japanese scanning communication aids (JSCA) --listed in order from non-specific to specifically dedicated products.

However, AAC was not always used in appropriate and adequate ways because of insufficient support.[2] It should be noted that there are difficulties in acquiring experience in clinical practice because the number of patients is very low. So, we designed and evaluated a short-term education program with practical experiences for students in multiple health-care fields. [1,3]

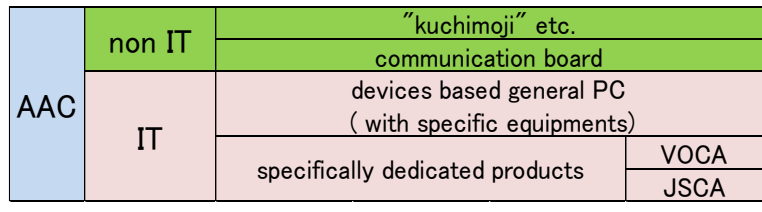

AAC: $\quad$ augmentative and alternative communication IT: information technology

PC: personal computer

VOCA: portable voice output communication aid

JSCA: Japanese scanning communication aid

Figure 1: Conceptual scheme of AAC in Japan

\section{OBJECTIVE}

In this report, we focus on the differences and transition of the visual analog scale (VAS) as the sense of burden. We aimed to clear and dissolve the factor of burden in communication, through students' understanding.

In addition, we evaluated and maintained the effects of understanding the burden of communication through practical experiences by re-learning this program. 


\section{METHOD}

\subsection{Outline of the Education program}

Our education program consists of two lecture sessions and one experience session that includes a three method communication trial (shown in Table 1). There are a few topics, group discussions for retrospection after topics and self-evaluation of burden, in each session.

We recorded the following: (1) sense of burden (using $100 \mathrm{~mm}$ VAS) before/after experiences and (2) the number of characters transmitted about three methods in Session II. Additionally, we imposed a Pre-/Post-test before Session I/after Session III, in order to confirm whether the students understood the lecture with burden VAS.

Table 1: Curriculum of education program

I. Lecture of introduction
-About ALS pathology and actual circumstances care
-Multidisciplinary cooperation of Communication support
II. Practical exercises of communication
-Cross-shaped (flick-type) communication board (Flick)
-Comprised an oral and eye-blink method without a board
(Kuchi-moji)
-Japanese scanning communication aid (JSCA)
III. Lecture of detailed exposition
-Selecting and adjusting communication aids(CA) and public
support systems
-Contents of the support corresponding to the
progression/stage of ALS

The participants are undergraduate students in health-related disciplines such as nursing, medical, rehabilitation and clinical psychiatry. This program was held four times every 6 months and they learned this education program two consecutive times (as shown in Figure 2.). Therefore, all participants were beginners in the first period. In the second period, there were experienced participants and beginners together.

Figure 2: Protocol of lecture and evaluation

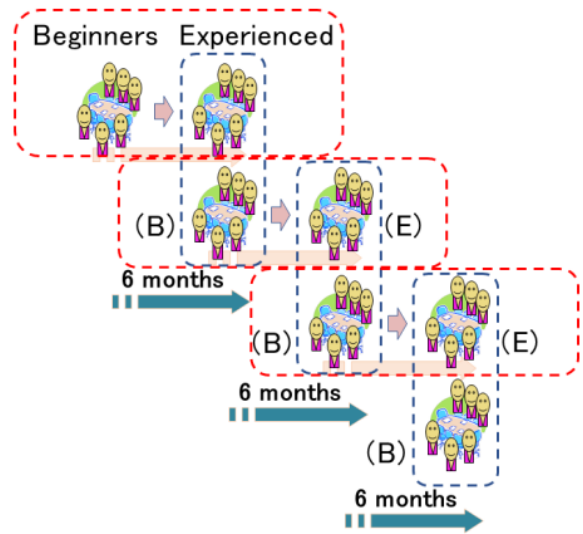

\subsection{Evaluate of effect}

Attributes of participants are shown in Table 2. We compared the VAS of each method to clear the factor for a high sense of burden, before/after experiences to clear the effect of learning and 1st/2nd experiences to clear the effect re-learning. Self-evaluation VAS after the experience was subdivided after Period 2. Hence, we compared it only to period 2 and period 3 . VAS is shown as average +/- SD with p-value in tables 3 to 7 .

Data analysis was performed using a statistical application, SPSS version 25. Statistical significance of paired sample t-test was set at less than 0.05 .

Table 2: Attribute of participants

\begin{tabular}{|c|c|c|c|c|c|c|c|}
\hline Univ. & course & sex & $\begin{array}{l}\text { Period- } \\
0 / 1\end{array}$ & $\begin{array}{l}\text { Period- } \\
1 / 2\end{array}$ & $\begin{array}{l}\text { Period- } \\
2 / 3\end{array}$ & $\begin{array}{l}\text { Period- } \\
3\end{array}$ & Total(*) \\
\hline \multirow[t]{4}{*}{$\overline{\mathrm{MU}}$} & \multirow[t]{2}{*}{ Medical } & male & (4) & 2 & 1 & 0 & 3 \\
\hline & & female & (0) & 0 & 1 & 1 & 2 \\
\hline & \multirow[t]{2}{*}{ nursing } & male & (0) & 0 & 0 & 1 & 1 \\
\hline & & female & (2) & 4 & 4 & 1 & 9 \\
\hline \multirow[t]{2}{*}{ SUMS } & \multirow[t]{2}{*}{ nursing } & male & & 0 & 0 & 0 & 0 \\
\hline & & femare & & 6 & 6 & 2 & 14 \\
\hline \multirow[t]{4}{*}{ CGU } & \multirow[t]{2}{*}{ nursing } & male & & 1 & 0 & 0 & 1 \\
\hline & & female & & 2 & 3 & 3 & 8 \\
\hline & \multirow{2}{*}{$\begin{array}{l}\text { Rehabili- } \\
\text { tation }\end{array}$} & male & & 2 & 0 & 1 & 3 \\
\hline & & female & & 1 & 3 & 2 & 6 \\
\hline \multirow[t]{3}{*}{ AUE } & clinical & male & & 1 & & & 1 \\
\hline & psychiatry & female & & 4 & & & 4 \\
\hline & Subtotal & & (6) & 23 & 18 & 11 & 52 \\
\hline
\end{tabular}

MU : $\quad$ Mie University

SUMS : Suzuka University of Medical Science

CGU : Chubu Gakuin University

AUE : Aichi University of Education

\subsection{Ethical approval}

This study was approved by the Research Ethics Committee of the Faculty of Medicine, Mie University (No. 3245, March 2018), Chubu Gakuin University \& College (No. D18-0004, June 2018).

\section{RESULTS}

\subsection{Compared by method}

The transitions of VAS before/after experience on three methods are shown in Table 3. The before experience had significant differences in each method. The highest VAS was Kuchimoji, that doesn't use any tools, and lowest was JSCA as an IT based AAC.

The VAS after experience was higher than before on every method. On Flick and Kuchimoji, VAS for the role of presenter was higher than the VAS for the role of the confirmer. Significant differences were found between the before and after (presenter), but none found between before and after (confirmer).On JSCA, the highest VAS was recorded after experience (before adjustment of scanning speed), and after adjustment, the VAS was transited lower. 
Table 3: Transitions of VAS in overall participants $(\mathrm{N}=70)$

\begin{tabular}{|c|c|c|}
\hline & $\begin{array}{l}\text { Before } \\
\text { experience: }\end{array}$ & $\begin{array}{r}\text { After experience(upper) Presenter } \\
\text { (lower) Confirmer }\end{array}$ \\
\hline Flick & $24.2+/-18.2$ & $\left.\begin{array}{ll}36.8+/-22.2 & \mathrm{p}=0.000^{* *} \\
28.3+/-17.1 & \mathrm{p}=0.185\end{array}\right\} \mathrm{p}=0.001^{*}$ \\
\hline $\begin{array}{l}\text { Kuchi- } \\
\text { moji }\end{array}$ & $43.1+/-20.2$ & $\begin{array}{l}51.8+/-27.5 \\
45.1+/-22.8 \\
\end{array}$ \\
\hline & $\begin{array}{l}\text { Before } \\
\text { experience: }\end{array}$ & $\begin{array}{l}\text { After experience(upper) Before Adjustment } \\
\text { (lower) After Adjustment }\end{array}$ \\
\hline JSCA & $16.3+/-15.4$ & $\left.\begin{array}{lll}34.6+/-26.1 & p=0.000^{* *} \\
20.1+/-14.8 & p=0.032^{*}\end{array}\right\} p=0.032 *$ \\
\hline
\end{tabular}

\subsection{Compared by experience}

\section{(1) Beginners group}

There were 29 beginners, who had not experienced this education program. Their VAS before/after experience in the three methods is shown in Table 4. There was no significant difference between Flick and JSCA at before experience. This was a specific trend.

The VAS after experience was higher than before on every method and it was the same trend as the overall comparison. Although there was a high significant difference between the before and after (confirmer) on Flick, it was not the same trend as the overall comparison.

Table 4: Transitions of VAS in beginners group ( $\mathrm{N}=29)$

\begin{tabular}{|c|c|c|}
\hline & $\begin{array}{l}\text { Before } \\
\text { experience: }\end{array}$ & $\begin{array}{r}\text { After experience(upper) Presenter } \\
\text { (lower) Confirmer }\end{array}$ \\
\hline Flick & $19.4+/-14.9$ & $\left.\begin{array}{l}\mathrm{p}=0.000^{* *} \\
\mathrm{p}=0.015^{*}\end{array}\right\} \mathrm{p}=0.010^{*}$ \\
\hline $\begin{array}{l}\text { Kuchi- } \\
\text { moji }\end{array}$ & $40.7+/-18.3$ & $\begin{array}{l}56.8+/-27.0 \\
47.5+/-20.0 \\
\end{array}$ \\
\hline & $\begin{array}{l}\text { Before } \\
\text { experience: }\end{array}$ & $\begin{array}{l}\text { After experience(upper) Before Adjustment } \\
\text { (lower) After Adjustment }\end{array}$ \\
\hline JSCA & $15.1+/-8.8$ & $\left.\begin{array}{lll}36.1+/-26.4 & p=0.000^{* *} \\
20.8+/-14.3 & p=0.046^{*}\end{array}\right\} \mathrm{p}=0.001^{* *}$ \\
\hline
\end{tabular}

\section{(2) Experienced group}

There were 41 participants, who had experienced this education program. Their VAS before/after experience in the three methods is shown in Table 5. Before the experience, there were significant differences among each method - same trend as the above.

The Average VAS of after experience was higher than the before experience on every method, except between the before and after (confirmer) on Flick and Kuchimoji. However, there were no significant differences except between before and after (before adjustment) on JSCA.
Table 5: Transitions of VAS in experienced group $(\mathrm{N}=41)$

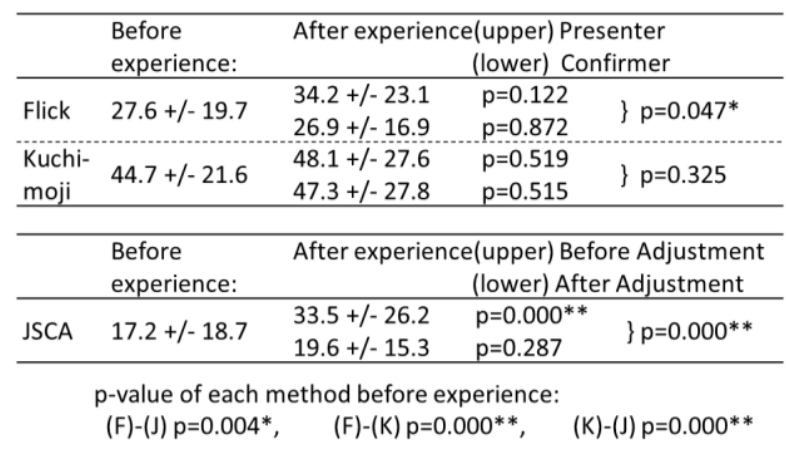

\section{(3) Transition from a beginner to an experienced student}

There were 18 participants, who had experienced this education program two times. Their VAS of the 1st(beginner)/2nd(experienced) are shown in Table 6 . There was significant difference only in the after (presenter) of Kuchimoji.

Table 6: Compare of VAS in two times $(\mathrm{N}=18)$

\begin{tabular}{lllll}
\hline & & 1st(beginner) & 2nd(experienced) & $\mathrm{p}$-value \\
\hline Flick & Before & $20.1+/-14.2$ & $27.4+/-16.0$ & $\mathrm{p}=0.193$ \\
& After (p) & $45.8+/-20.9$ & $42.9+/-21.7$ & $\mathrm{p}=0.616$ \\
& After (c) & $36.1+/-16.6$ & $30.8+/-17.1$ & $\mathrm{p}=0.353$ \\
$\begin{array}{l}\text { Kuchi- } \\
\text { moji }\end{array}$ & Before & $43.9+/-17.3$ & $43.1+/-23.7$ & $\mathrm{p}=0.905$ \\
& After (p) & $59.0+/-28.1$ & $42.6+/-27.0$ & $\mathrm{p}=0.010^{*}$ \\
& $\begin{array}{l}\text { After (c) } \\
\text { JSCA }\end{array}$ & $53.9+/-22.2$ & $39.6+/-25.5$ & $\mathrm{p}=0.053$ \\
& $\begin{array}{l}\text { Before } \\
\text { experience }\end{array}$ & $15.7+/-9.8$ & $20.0+/-20.1$ & $\mathrm{p}=0.298$ \\
& $\begin{array}{l}\text { Before } \\
\text { Adjustment }\end{array}$ & $39.2+/-27.2$ & $32.2+/-24.3$ & $\mathrm{p}=0.291$ \\
& $\begin{array}{l}\text { After } \\
\text { Adjustment }\end{array}$ & $21.2+/-13.3$ & $20.3+/-15.4$ & $\mathrm{p}=0.794$ \\
\hline
\end{tabular}

Table 7 shows continuity after the 1 st experience to before the 2 nd experience; with a gap of 6 months. There was lower significant difference in between the 1st-after (presenter) and 2nd-before on Flick and Kuchimoji.

Table 7: Transitions of VAS between two times $(\mathrm{N}=18)$

\begin{tabular}{|c|c|c|c|}
\hline & $\begin{array}{l}\text { 1st-After experience } \\
\text { (upper) Presenter } \\
\text { (lower) Confirmer }\end{array}$ & $\begin{array}{l}\text { 2nd-Before } \\
\text { experience }\end{array}$ & $\mathrm{p}$-value \\
\hline Flick & $\begin{array}{l}45.8+/-20.9 \\
36.1+/-16.6\end{array}$ & $27.4+/-16.0$ & $\begin{array}{c}p=0.008 * * \\
p=0.050\end{array}$ \\
\hline $\begin{array}{l}\text { Kuchi } \\
\text {-moji }\end{array}$ & $\begin{array}{l}59.0+/-28.1 \\
53.9+/-22.2 \\
\end{array}$ & $43.0+/-23.0$ & $\begin{array}{l}p=0.019^{*} \\
p=0.157\end{array}$ \\
\hline & $\begin{array}{r}\text { 1st-After experience } \\
\text { (After Adjustment) }\end{array}$ & $\begin{array}{l}\text { 2nd-Before } \\
\text { experience }\end{array}$ & p-value \\
\hline JSCA & $21.2+/-13.3$ & $20.0+/-20.1$ & $p=0.782$ \\
\hline
\end{tabular}




\section{DISCUSSION}

We presume that the VAS before practice is the burden that the participants impression. There were significant differences between each method in the overall and experienced groups.

However, in the beginners' group, there was no significant difference between Flick and JSCA, and both were low. Therefore, we guessed; they thought communication would be possible by using some tools as an impression before the experience. There was a partner on Flick and Kuchimoji. Hence, their burden was a difference between the presenter role and the confirmer role. Under all conditions, the VAS of the presenter role had a higher burden than the confirmer role.

A comparison of the sense of burden before and after the experience showed a difference in trend between the beginners and the experienced. In the experienced group, there was no significant difference in the sense of burden before and after the experience (except JSCA). On JSCA, VAS of after experience with default values transitioned to high. When after the experiences, by adjusting the speed to their own good, the VAS translated to low. Therefore, not being able to communicate at your own pace may be a factor of high burden.

There was no significant difference between the 1st (as beginner) and 2nd time (as experienced) same evaluation item (except Kuchimoji after an experienced role of the presenter). Kuchimoji after an experienced role of a presenter the1st time had the highest VAS, which transitioned to low the 2nd time.

We continuously evaluated the VAS transitions between after the 1st experience to before the 2nd experience. There was lower significant difference only at the Frick and Kuchimoji role of presenters. The reason for no significant difference in others could be because the participants understood the factor of burden and found the solution during the first learning experience. In others, there was no significant difference. Therefore, this indicates that the results were maintained employing the 6 months apart process, suggesting the effect of repeated learning.

\section{CONCLUSION}

We designed a short-term education program with practical experiences on communication support for patients with neurodegenerative disorders, especially ALS, and implemented it for students in multiple healthcare disciplines at four universities.

We found the burden and the points of improvement through communication experiences in three different ways; (1) VAS was lower in case of using tools, (2) VAS of the presenter role had a higher burden than the confirmer role and (3) not being able to communicate at your own pace could be a factor of high burden.

VAS transitions between the 1st to before 2nd experience had no or lower significant difference, hence short-term education programs with practical experiences can be useful.

However, it should be understood that not all VAS are inexpensively low. The participants did not eliminate the burden but they understood that there were high burden communication methods.

\section{ACKNOWLEDGMENTS}

This study was conducted as of a project by the Scientific Study Furtherance Fund grant, Japan Society for Promotion of Science, No. 17K08914. Title: Making a brief education course for communication for severely disabled patients with ALS (leader, Yugo Narita).

We would like to thank Editage (www.editage.com) for English language editing.

\section{REFFERENCES}

[1] Narita Y., Nakai M., Imura T., et al.: Education Program for Students in Multiple Health-care Fields to Support Communication with Patients with Amyotrophic Lateral Sclerosis -- Can a Pre-/Post-test Evaluate Knowledge Gained through Education Sessions?--. International Journal of Affective Engineering, 18 (3), pp.161-170, 2019.

[2] Imura T.: Analysis of the situation and support for using communication aids in ALS patients. Journal of Japan Intractable Illness Nursing Society, 20 (2), pp.125-138, 2015. (in Japanese with English abstract)

[3] Imura T. , Urisu A., Narita Y., et al.: Proposal of Short-Term Education Training Programs with Practical exercises to Support Communication for Intractable Neurological Diseases -- Differences in Sense of Burden and Their Factors Before-and-After Training --. Chubu Gakuin University and Chubu Gakuin College Journal of Educational Research and Practice, 5, pp.205-214, 2019. (in Japanese) 